\section{OPEN ACCESS}

Edited by:

G. Darrel Jenerette University of California, Riverside,

United States

Reviewed by:

Rafal Stryjek,

Institute of Psychology (PAN), Poland

Adam James Bates,

Nottingham Trent University,

United Kingdom

*Correspondence:

Michael H. Parsons

parsons.hmichael@gmail.com

Specialty section:

This article was submitted to Urban Ecology,

a section of the journa

Frontiers in Ecology and Evolution

Received: 23 June 2018 Accepted: 04 September 2018

Published: 27 September 2018

Citation:

Parsons MH, Banks PB, Deutsch MA and Munshi-South J (2018) Temporal and Space-Use Changes by Rats in Response to Predation by Feral Cats

in an Urban Ecosystem

Front. Ecol. Evol. 6:146.

doi: 10.3389/fevo.2018.00146

\title{
Temporal and Space-Use Changes by Rats in Response to Predation by Feral Cats in an Urban Ecosystem
}

\author{
Michael H. Parsons ${ }^{1 *}$, Peter B. Banks ${ }^{2}$, Michael A. Deutsch ${ }^{3}$ and Jason Munshi-South ${ }^{4}$ \\ ${ }^{1}$ Department of Biological Sciences, Fordham University, Bronx, NY, United States, ${ }^{2}$ School of Life and Environmental \\ Sciences, University of Sydney, Sydney, NSW, Australia, ${ }^{3}$ Medical and Applied Entomology, Arrow Exterminating Company, \\ Inc. Lynbrook, NY, United States, ${ }^{4}$ Department of Biological Sciences and the Louis Calder Center-Biological Field Station, \\ Fordham University, Armonk, NY, United States
}

Feral cats (Felis catus) are predators that cause widespread loss of native wildlife in urban ecosystems. Despite these risks, cats are commonly released as control agents for city rats (Rattus spp.). Cats can influence their prey directly by killing or indirectly through changes to feeding or space-use. However, cats prefer defenseless prey, and there are no data suggesting that cats influence large $(>300 \mathrm{~g})$ urban rats. We used a pre-existing radiofrequency identification assay (microchipped rats and field cameras) and ethograms to assess the impact of cats, including temporal and space use patterns, on an active rat colony. From Dec 27, 2017 through May 28, 2018 we captured 306 videos of pre-identified cats and/or rats that shared the same space. There were three instances of predation and 20 stalking events. Logistic regression showed the likelihood of a rat being seen on a particular day is associated with the number of cats seen on the same day $(O R=0.1, p<0.001)$ or previous day $(O R=0.15, p<0.001)$. Space-use was also impacted. For every additional cat sighting, a rat is 1.19 times more likely to move in the direction of shelter. Our findings of low levels of predation support why ecologists believe the risks to native wildlife outweighs any benefits of releasing cats. Even though rats were less likely to be seen, they simply shifted their movements and remained present in the system. Our findings that cat presence led to fewer rat sightings may explain the common perception of their value as rat-predators despite the associated risks.

Keywords: city rats, Felis catus, New York city rat, Norway rats, Rattus norvegicus, urban wildlife interactions

Pussycat, pussycat, where have you been?
I've been to London to visit the Queen.
Pussycat, pussycat, what did you there?
I frightened a little mouse under her chair.
... James W. Elliot (1870)

\section{INTRODUCTION}

Cat predation on rodents, particularly mice (Mus, Peromyscus spp.), is among the most recognized models of predator: prey interactions, inspiring nursery rhymes, cartoons and public perceptions. Many non-trained observers, however, cannot tell the difference between mice which weigh 20-35 g (Zielinski et al., 1992) and city rats which often weigh 10 times as much (Parsons et al., 2017; Combs et al., 2018). This misconception may be partly responsible for cats being widely considered 
as a "natural" control tool for rats. However, predators have an energy budget, whereby their caloric intake is maximized (Jeschke et al., 2002) against potential risks from large or defensive prey (Embar et al., 2014). And thus, cats may be more likely to deplete birds and easier meals (e.g., smaller mammals and their young) before moving to rats. Further, as domesticated animals, cats are well adapted to survive on handouts from people (Montague et al., 2014). The domestication of cats, and abundance of easier to obtain alternative foods cast doubts on cats' inclination to prey on city rats and suppress their numbers.

Feral cats can impact on the dynamics of their prey, but there is much stronger data indicating that cats influence native wildlife (Kauhala et al., 2015; Kikillus et al., 2017) than city rats. For example, in Australia (Davies et al., 2017) and the US (Loss et al., 2013), cats represent the greatest source of anthropogenic mortality for native birds and mammals. This has been historically recognized on island ecosystems where cats are evolutionarily novel (Woinarski et al., 2017), but is also true for some continental (Loss and Marra, 2017) and urban systems (Pillay et al., 2018). At current rates of human urbanization, the latter are the fastest growing ecosystems in the world, with more than $70 \%$ of people expected to live in cities by 2050 (Zhou et al., 2013). In contrast to the native vertebrates most impacted by cats, city rats have coexisted with cats for centuries. These rats are well adapted to urban ecosystems; they represent a large prey item for all but the boldest cats and can defend themselves. Yet some densely populated cities such as Chicago, IL., USA are widely reported in the media (Glanton, 2017) as making mass efforts to use cats as rat control tools. Not only is releasing cats a risk for wildlife, but it also invites welfare concerns for the cats themselves. For instance, it is common knowledge that a well-fed and cared for cat may coexist peacefully alongside rats. Thus, those who employ cats as pest-control solutions may intentionally avoid feeding them in order to prompt them to hunt (MP, pers. obs.). More conclusive evidence is necessary before cats can be justified as control instruments for rats.

Because of their larger size, city rats may be less vulnerable to cats than native rodents. Feral cats tend to prefer smaller prey, including smaller rodents with a $<250$ g threshold (Childs, 1986). Much of the evidence identifying cat impacts on Rattus species is from islands, where insular dwarfism may lead to animals be smaller than continental conspecifics (e.g., Foster's rule, Rozzi and Lomolino, 2017). For instance, Karl and Best (1982) examined 229 scats from feral cats on Stewart Island, New Zealand. Rats (Rattus spp.) occurred in 93\% of the scats (as compared to $44 \%$ birds). However, adult rats in these systems tends to be around $150 \mathrm{~g}$ (or half the size of a New York City rat; Parsons et al., 2017; Combs et al., 2018), including Polynesian rats (Rattus exulans) which are the smallest of the human-commensal Rattus. Similarly, Fitzgerald et al. (1991) examined 8 years of feral cat scats on Raoul Island. Ninety percent of the rats were Polynesian rats, with less than 10\% from the larger (though still smaller than occurs on mainland), Norway rat ( $R$. norvegicus).

Among the few continental studies that examined the influence of cats on rats, there were mixed results. In Finland, researchers found that $72 \%$ of all prey brought home by cats were rodents. However the authors did not distinguish between mice and rats, and indicated that almost half of all kills belonged to exceptionally large cats (Kauhala et al., 2015). Experimental release of 20 native long-haired rats (Rattus villosissimus) in Australia led to rapid extirpation by cats (Frank et al., 2014). However, these rats were also about half the size ( $150 \mathrm{~g})$ of most city rats. Also in Australia, the analysis of stomach contents from 80 feral cats revealed $80 \%$ of their diet was from rodents, but the majority of rats were identified as long-haired rats (Yip et al., 2015).

There is no evidence that cats can directly suppress populations of city rats. However, predation impacts can also arise indirectly via non-lethal effects on prey from the risks of predation. The scent from cats (Felus catus) alone is enough to lower reproductive capacity in some mice (Kelliher and Wersinger, 2009; Voznessenskaya, 2014) and rats (Naidenko et al., 2003; Voznessenskaya et al., 2003; Voznessenskaya, 2014). Predation risk can also limit access to food (Herman and Valone, 2000), an effect that could be exaggerated in urban systems. In the urban environment, rats must navigate exposed environments when seeking new harborage or accessing food or water by some distance (unlike mice that can metabolically produce their own water; Schmidt-Nielsen and O'Dell, 1961, rats may drink up to $30 \mathrm{ml}$ water/day, Siegel and Stuckey, 1947). Avoidance of exposed areas is common in many species of smaller, "vulnerable," animals (Apfelbach et al., 2015), from small marsupials in Tasmania (Parsons and Blumstein, 2010) to oldfield mice (Peromyscus polionotus) in Southern California (Orrock et al., 2004; Orrock and Danielson, 2009). It is thought the risk of predation drives fear of open spaces or full moons, where exposed, and forage less frequently or for shorter durations and remain closer to home (Orrock et al., 2004; Orrock and Danielson, 2009). However, evidence on the indirect effects from cats on city rats is also limited. Mixed predator scents from dogs and cats together, discouraged rodents from feeding trays, though the authors did not differentiate between mice (Mastomys natalensis) and ship rats ( $R$. rattus) (Themb'alilahlwa et al., 2017). More recently, Carthey and Banks (2018) showed that free living ship rats recognized cat odor, but showed no anti-predator responses either in vigilance or feeding behaviors, suggesting that rats took the risks to access resources.

Indeed, despite the prominent knowledge gaps that persist regarding city rats, such as the well described influence that pheromones have to influence the behavior and physiology of rodents (Hurst and Beynon, 2004; Takács et al., 2016), almost no research has been performed in situ in the urban ecosystem (Parsons et al., 2017). This is because, if rats appear in the city, they exist on property owned by someone. The owners are not eager to allow experimentation by researchers unless the research leads to extermination. Thus, researchers have not had any means of studying urban rats in their natural habitat such as the Frank et al. (2014) experiment, and thereby providing stronger evidence for the influence of cats at a given location, either directly or indirectly, on city rats. 


\section{OBJECTIVES}

In this paper we investigate how feral cats directly or indirectly impact urban rats. In our longitudinal rat research program in New York City, USA, we have access to an active rat colony inside a waste management facility where, via a pre-existing radio frequency identification (RFID) study, we live-trap, microchip, and release animals while studying their individual life histories, population demographics and behaviors (Parsons et al., 2017). Additionally, there are nearly two dozen feral cats that have lived in close proximity to this research site for several years. Specifically, we assessed whether variations in the number of cats present on a given day, or preceding day, would influence the number of rats observed, or whether the number of rats or humans would be a predictor of the number of cats seen. Our secondary interests were to determine whether the presence of cats had any effect on the prevalence of 8 common rat behaviors or direction of movement across a frequently utilized runway of the main colony.

\section{METHODS}

\section{Study Area}

New York City (NYC), $40.71^{\circ} \mathrm{N}, 74.01^{\circ} \mathrm{W}$, is the second most populous city in North America at roughly 2,000 people/square mile (Griffith and Wong, 2007). With $\sim 8.5$ million inhabitants, it consists of 5 boroughs located between the Hudson river and Atlantic Ocean. The climate has warm, moist summers (summer monthly highs average $27.8^{\circ} \mathrm{C}$ with $19.3^{\circ} \mathrm{C}$ minima) and cold winters (average monthly max is $5.0^{\circ} \mathrm{C}$ and $-1.5^{\circ} \mathrm{C}$ minima) with an annual precipitation of $50-200 \mathrm{~cm}$ (NOAA). Brown rats (Rattus norvegicus) arrived from Europe by ship between 1700 and 1750 (Puckett et al., 2016; Combs et al., 2018). Because they had few natural predators, they rapidly reached pest status. Predators include red tailed hawks (Buteo jamaicensis), coyotes (Canis latrans), red foxes (Vulpes vulpes) domestic dogs (especially terriers; Canis familiaris), mustellids such as the fisher (Pekania pennanti) and escaped pet ferrets (Mustela putorius furo) and feral cats (Felis domesticus). This area has been referred to as one of the "rattiest cities" on Earth (Robert Corrigan, Department Health and Mental Hygiene, NYC, ret.). This colloquial designation is the result of abundant wastes left out overnight, the amount of rubbish left outdoors and in parks, and the relative lack of predators.

\section{Study Site}

We received permission to utilize an industrial waste recycling site in Brooklyn, a south-eastern borough of NYC. The study site is located on one of the properties owned by Waste Management (WM). WM is a provider of comprehensive waste management services in North America, providing services that range from collection and disposal to recycling and renewable energy generation. As part of their commitment of "supporting customers and communities," WM has agreed to host the New York City rat research project at Fordham University. The recycling plant is an indoor, semi-enclosed building that, as in any industrial, disturbed area, provides ample shelter for rodents.

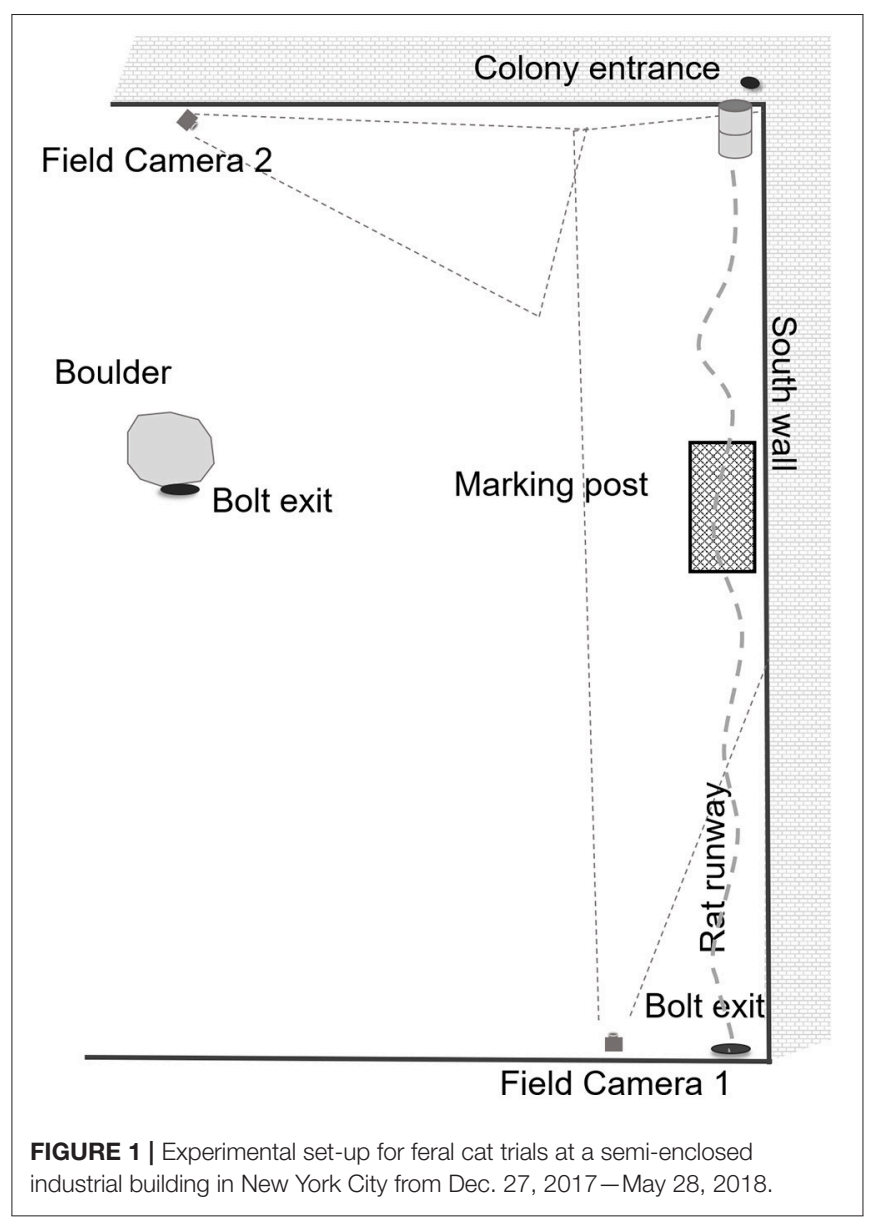

Operations are ongoing day and evening, it is noisy from trucks and excavators and may be noxious from collected rubbish. There is a continuous supply of potential food for small animals, as central operations require that rubbish be brought in, sorted, recycled and disposed of, or shipped out. The site is not climatecontrolled and animals may burrow under floors and deep within the walls, thus temperatures inside are variable depending on location. Our primary rat colony (Figure 1) is in a mostly unlit area that is dimly lit or dark day and night. The primary food supply is located immediately to the west of the main burrows.

\section{Experimental Design}

We have an ongoing rat research program at multiple sites in NYC, assessing rat behaviors in relation to scents, while producing ethograms and activity budgets to document city rat behaviors in the natural environment. During the latter part of our previous trials (Parsons et al. unpublished data), several cats entered our research area and persisted throughout the study. Instead of halting experiments, we designed an investigation to quantify the influence of cats on the rat behaviors and movements.

Our methods of live-capture and anesthetization have previously been reported (Parsons et al., 2015, 2016; Parsons et al., unpublished data). An RFID central processor with data logger (PADAR; UID, Chicago, IL, USA) had also been 
permanently installed (Parsons et al., 2016). The rat colony (Figure 1) had an estimated 120-150 rats, based on 37 live captures (the majority of which were used in another study (Parsons et al., unpublished data). The average weight was 337 $\pm 13.6 \mathrm{~g}$ with average length of $375 \pm 4.2 \mathrm{~mm}$ (including tail). Additionally, animals from this population are active during most of the day and evening, with some individuals actively recording their presence at RFID sensors the same day and night.

We deployed two infrared field cameras (Browning Strike Force Elite HD) with a $0.4 \mathrm{~s}$ trigger-speed, aimed from Northeast to Southeast and West to East across an active, well-established, rat colony inside the urban industrial center (Figure 1). We recorded these data from December 29, 2017 when the first cats were identified until May 28, 2018. We counted the number of triggers by cats, rats and people, and converted these to percent of total videos captured as our primary response variables, while using day as our observation period. We only recorded intervals where at least one rat or cat was captured in order to account for false triggers by researchers, wind, and birds on days when there was otherwise no animal activity.

We also examined whether a cat seen on a previous day influences the rat seen on the subsequent day. We calculated a lag period for cats by subtracting 1 day from when each rat was captured (e.g., we calculated the number of rat triggers as our response in the fitted line plot and used the lag of cats as the predictor). We also calculated a lag period for rats to determine whether their presence on a subsequent day predicted the number of cats.

All videos were reviewed and manually scored by the same observer. We first noted that the presence of the colony entrance
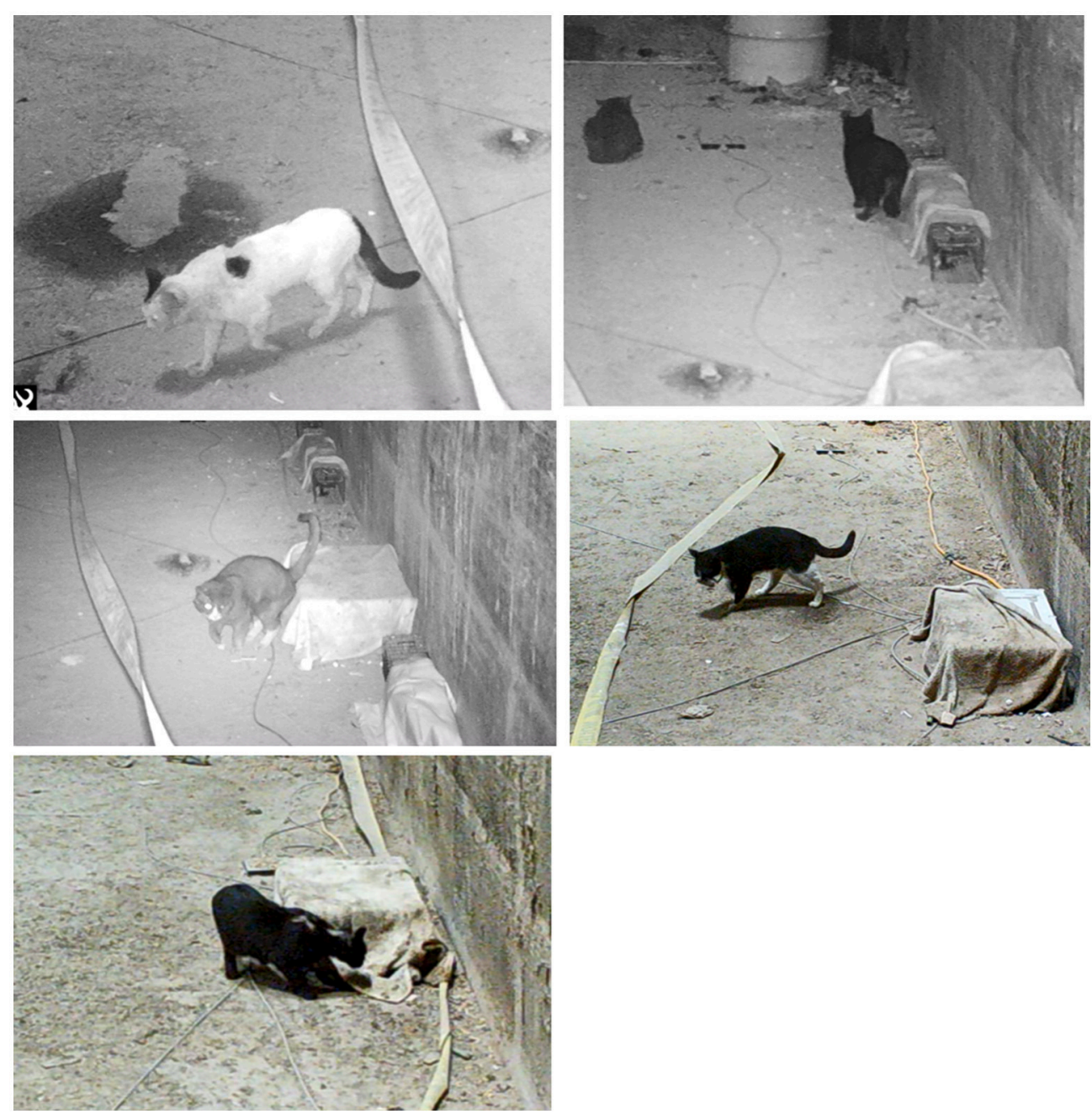

FIGURE 2 | Coat patterns of five feral cats and subsequent ethogram used to score their behaviors at a semi-enclosed industrial building in New York City from Dec. 27, 2017-May 28, 2018. Cat behaviors scored (modified from Stanton et al., 2015) include walking (w): forward locomotion where animal moves slowly. Running (r): animal uses forward locomotion at a rapid gait. Stalking (s): slow forward motion in crouched position, with head low and eyes focused on potential prey. Predation (p): hunting or killing that leads to a direct kill. Sniffing (s): cat smells floor or object by inhaling air through the nose. Feeding (f): animal ingests food, usually from floor. Sitting (s): animal is immobile in upright position. Marking (m): while standing with tail raised vertically, cat releases jet of urine backwards onto a substrate of an object. Tail may quiver as urine is released. 
(harborage) was to the east (Figure 1) across the south wall, and the bolt exit (relief entrance when the main entrance is blocked) was to the North. Whereas, the typical foraging and water sources the animals utilized were refuse heaps to the west. While scoring cat videos, we recorded all instances of eight primary cat behaviors (Figure 2): walking, running, stalking, chasing (predation), sniffing, feeding, sitting, marking (or overmarking) and direction of movement of animal. As these videos varied in length, some for only seconds, we only recorded instances of an event, and not the duration of a behavior. While scoring rat videos (Figure 3), we recorded all instances of walking, running, freezing, drinking, feeding, sitting, and being chased/predation. Likewise, we recorded direction of movement of the animal. This work was performed under IACUC guidelines for ethical conduct in the care and use of nonhuman animals in research (Fordham IACUC JMS 17$01)$.

\section{Statistics}

We performed binary logistic regressions to assess whether the proportion of rat triggers were related to the proportion of cat triggers in a given day, whether the proportion of previous day cat sights was related to the proportion of rat sightings on the current day, whether the proportion of rat sightings the previous day was related to the proportion of cat sightings on the current day, and whether the percent of people triggers was associated with the proportion of rats in a given day. We also used binary logistic regressions to determine the relationships between cats and the 8 common rat behaviors (except chase/predation which only occurred 3 times) and direction of movements. Statistical significance (alpha) was set at $P \leq 0.05$ and all descriptive and inferential analyses were conducted using Minitab V. 17 (State College, PA).

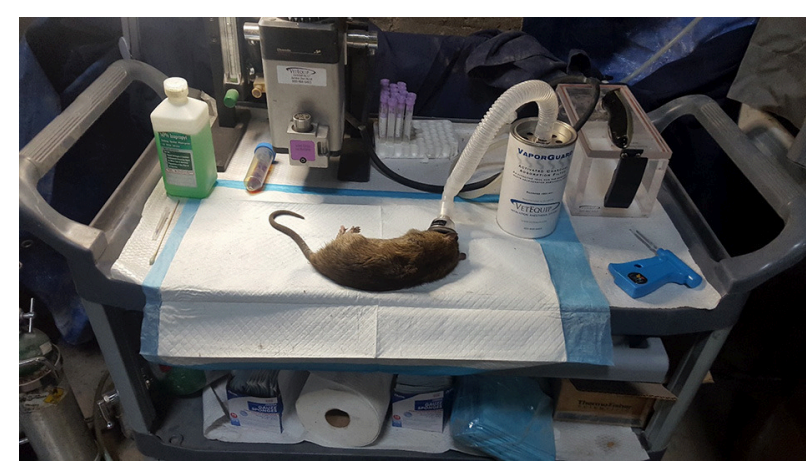

FIGURE 3 | Anaesthetization equipment and typical > $330 \mathrm{~g}$ rat captured along with ethogram used to score rat behaviors at a semi-enclosed industrial building in New York City from Dec. 27, 2017-May 28, 2018. Rat behaviors scored include walk (w): forward locomotion where animal moves slowly. Run(r): forward locomotion where animal moves at a faster pace, forearms extended. Freeze/stop (f): rats cease activity and become immobile, usually in response to a perceived threat. Drink (d): animal consumes water or other liquid source, usually from puddles. Sniff (s): animal smells object by inhaling air through the nose. Feed (f): animal ingests food particle, often from the floor surface. Sit (s): animal is in relaxed posture, immobile, and may be on haunches with forearms extended.

\section{RESULTS}

A total of 306 videos taken over 79 days were scored. Five individual cats were identified based on color, markings and scar patterns (Figure 2). These animals first appeared on December 27 and remained throughout the study. On five occasions, three of the cats appeared on the same day. There were three predation attempts by two cats (one each had a successful attempt) and one unsuccessful attempt. All five cats participated in stalking events (20).

During the period when cats were present (Dec 27-May 28), the number of cats on a given day influenced the likelihood of rats to be seen on the same day (Figure 4, OR $=0.01$; 95\% CI $[0.00,0.02], p<0.001)$. For every $1 \%$ increase in the number of cats on a given day, it is 100 times less likely that a rat will trigger a camera on that day. Additionally, the number of cats on a previous day inversely predicted the number of rats $(O R=0.15$; $95 \%$ CI $[0.06,0.34], p<0.001)$. Every $1 \%$ increase in the number of cats seen on the previous day results in a rat being 6.6 times less likely to be seen on that day. The number of rats seen on a given day did not predict the number of cats seen on the following day $(\mathrm{OR}=0.62, p>0.1)$, nor did the number of people seen on a given day influence the likelihood of rats being seen on the same day $(\mathrm{OR}=0.44, p>0.1)$.

\section{Behaviors and Space-Use}

Two hundred fifty-nine instances of cat behaviors were recorded (Table 1). Among these behaviors, 46.3\% (120) included walking in an eastward or westward direction beginning or ending near the rat colony entrance. Two videos culminated with the cat's head encroaching into the rat colony entrance. We found $27.4 \%$ of recorded cat behaviors (71) included sniffing. This behavior was performed across the open space floor and included two objects that were commonly over-marked. Two cats (Figure 1) overmarked the central object in the picture (the RFID enclosure) and occasionally perched on the unit, while the other three cats marked the bucket beside the colony entrance. There were 20 stalking attempts and 3 predation attempts, though cats and rats only appeared in the same video fewer than 10 times. Two predation attempts were successful when cats plucked the animal from under a hiding spot (beside the marking object), the lone predation attempt on the open floor was a failure when the rat stopped running, and the cat also ceased the chase, only to stare at it. Because the number of rats seen on a given day did not predict the number of cats seen on the following day, we did not assess number of rat sightings as predictors of any specific cat behavior.

On the other hand, because the number of cats did predict rat sightings, we examined how cat sightings varied with individual rat behaviors. The number of cats on a given day influenced the number of rats moving in an eastward direction toward their colony (Table 2; OR $=1.19 ; 95 \%$ CI $[1.00,1.41], p<0.05)$. Walking, a more conservative measure of locomotion than potentially running into a predator, was the only other behavior to vary (positively) with cat sightings. 


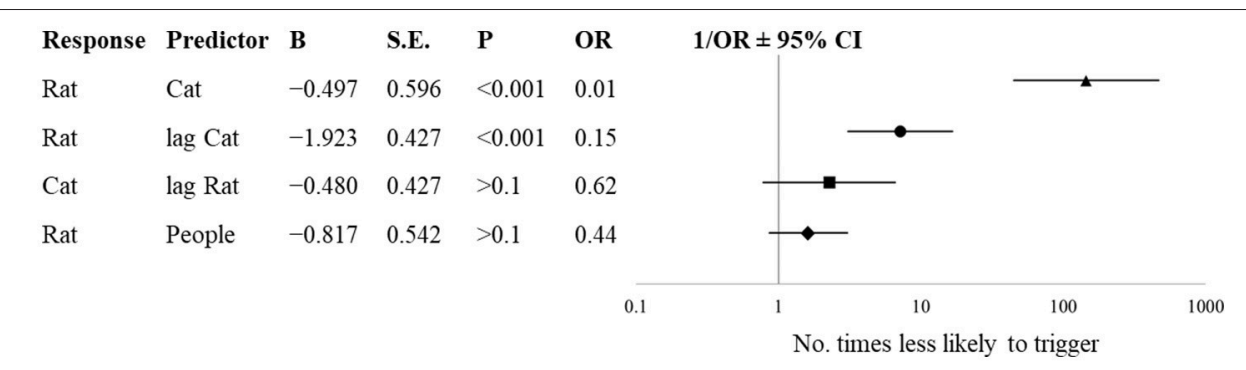

FIGURE 4 | Forest plot and likelihood estimates from binary logistic regressions with varied predictors at a semi-enclosed industrial building in New York City from Dec. 27, 2017-May 28, 2018. Lag refers to sightings on the preceding day.

TABLE 1 | Instances of recorded behavior of cats at a semi-enclosed industrial building in New York City from Dec. 27, 2017-May 28, 2018.

Cat ID Black Gray Scars $\begin{aligned} & \text { Black/ White Unknown Total } \\ & \text { white }\end{aligned}$

\begin{tabular}{|c|c|c|c|c|c|c|c|}
\hline \multicolumn{8}{|c|}{ BEHAVIOR } \\
\hline Walking & 14 & 46 & 6 & 21 & 27 & 6 & 120 \\
\hline Running & 2 & 1 & 0 & 3 & 2 & 0 & 8 \\
\hline Stalking & 1 & 3 & 2 & 9 & 5 & 0 & 20 \\
\hline Predation & 0 & 1 & 0 & 1 & 1 & 0 & 3 \\
\hline Sniffing & 8 & 45 & 2 & 6 & 10 & 0 & 71 \\
\hline Feeding & 0 & 6 & 0 & 1 & 1 & 0 & 8 \\
\hline Sitting & 3 & 3 & 0 & 0 & 2 & 0 & 8 \\
\hline Marking & 7 & 3 & 2 & 4 & 5 & 0 & 21 \\
\hline \multicolumn{8}{|c|}{ DIRECTION } \\
\hline North & 1 & 3 & 1 & 5 & 14 & 2 & 26 \\
\hline South & 2 & 2 & 0 & 1 & 1 & 1 & 7 \\
\hline East & 8 & 9 & 3 & 14 & 14 & 1 & 49 \\
\hline West & 3 & 36 & 4 & 5 & 4 & 3 & 54 \\
\hline
\end{tabular}

Direction refers to direction focal animal moved out of view.

\section{DISCUSSION}

This study is the first research to document the direct and indirect influences of identifiable feral cats on a partially-identified population of city rats. This partly-enclosed urban ecosystem was under heavy pressure from cats, as evidenced by the number of cats present and the number of staking attempts from each cat throughout the study. These events occurred during all hours of the day and evening. Yet of the 259 instances of behavior recorded by cats over 79 days/nights, only 3 times did a cat pursue a rat-and only once across an open floor. We were surprised that an area where up to three cats patrolled within the same 24-h period, would have so few direct predation attempts. While field cameras often have a latency period and are not perfect at capturing all behaviors, the cameras did have a fast $0.4 \mathrm{~s}$ triggerspeed and the back and forth nature of the chase lends a high likelihood of capturing at least part of the process on video.

We were, at first, surprised that such low predation could result in significant changes in space use and activity time. The odds ratios were very high at predicting rat sightings when the cat was sighted either during a given day $(O R=0.01)$, or a
TABLE 2 | Likelihood estimates in Binary Logistic Regressions with number of cat sightings as predictor of behavior for rats at a semi-enclosed industrial building in New York City from Dec. 27, 2017-May 28, 2018.

\begin{tabular}{lccccccc}
\hline Behavior & Coef. & SE & $\mathbf{Z}$ & $\mathbf{P}$ & OR & Lower & Upper \\
\hline Walk & 0.191 & 0.088 & 2.17 & $\mathbf{0 . 0 3 0}$ & 1.21 & 1.02 & 1.44 \\
Run & -0.060 & 0.086 & -0.70 & 0.483 & 0.94 & 0.80 & 1.11 \\
Freeze & -0.144 & 0.159 & -0.90 & 0.366 & 0.87 & 0.63 & 1.18 \\
Drink & -17.46 & $5,568.95$ & -0.00 & 0.997 & 0.00 & 0.00 & $*$ \\
Sniff & 0.0302 & 0.095 & 0.32 & 0.751 & 1.03 & 0.86 & 1.24 \\
Feed & -17.521 & $3,990.70$ & -0.00 & 0.996 & 0.00 & 0.00 & $*$ \\
Sit & -17.466 & $5,568.95$ & -0.00 & 0.997 & 0.00 & 0.00 & $*$ \\
North & 0.122 & 0.107 & 1.14 & 0.254 & 1.13 & 0.92 & 1.39 \\
South & 0.160 & 0.119 & 1.34 & 0.181 & 1.17 & 0.93 & 1.48 \\
East & 0.171 & 0.086 & 1.98 & $\mathbf{0 . 0 4 7}$ & 1.19 & 1.00 & 1.41 \\
West & 0.176 & 0.093 & 1.90 & 0.058 & 1.19 & 0.99 & 1.43 \\
\hline
\end{tabular}

Direction refers to orientation that rat moves when exiting video. Bold number indicates the number of cats influenced this behavior at $p<0.05$. ${ }^{*}$ Refers to upper limit bring too large to display i.e., > 1,000.

preceding day $(O R=0.15)$. We might have expected the rats to be habituated to cats in much the same way they seem to be to human visitation. This, despite the fact, that humans were regularly trapping and releasing rats and when extermination was ongoing as mandated by the city. However, it is also well known that all animals, especially potential prey, overestimate their risks using "simple rules of thumb" (Bouskila and Blumstein, 1992). It is better to falsely assume an organism is dangerous (a false positive) than to assume a dangerous animal is harmless (a false negative) (Johnson et al., 2013). This is primarily because not being sensitive to predation can lead to the ultimate loss of fitness via predation (Bouskila and Blumstein, 1992).

The two successful predation events were likely with smaller individuals under the weight range $(<250 \mathrm{~g})$ identified by Childs (1986). Unfortunately, these two individuals were not microchipped and thus we had no measure of weight for them. Additionally, these animals were both captured in hiding beside or beneath cats' preferred marking locations. Thus, it is also possible the rats were sick from disease or baiting from bromadiolone poison. While the researchers have longitudinal access to the study sight, the site owners are legislatively-obligated to continue baiting, even while supporting scientific research. 
Baiting is a normal part of urban ecosystems in cities throughout the world, and this must be figured into any ecological findings.

At first it seemed counter-intuitive that walking would vary significantly and positively with the number of cats sighted. However, Figure 1 shows that rats could either walk across their runway using cover as they moved east, or potentially run into an ambush. In this context, walking is the more conservative means of locomotion. The animals were more likely to move eastward during heavy cat sightings because this is where the primary shelter and colony entrance is located (Figure 1).

We were mildly disappointed that the RFID station and histories of the previously chipped rats were not more useful to our predation study. However, the RFID set-up still served to give some indication of the number of animals that were present in an active colony and to show that their weights were collectively much greater than the $250 \mathrm{~g}$ upper limit (Childs, 1986). Had the antennas been baited with an attractant, the rats might have been more likely to activate their identification tags prior to inducing/performing a specific behavior. As it happened, we were in the process of evaluating a putative scent-deterrent (Parsons et al., unpublished data).

Given our results, we can only note that the public's continued confusion between rats and mice (Mus musculus and Peromyscus spp.) may be encouraging a poor, but risky (Woinarski et al., 2017) approach to rat control. It is clear that although the rats were seen less frequently where we had our cameras placed (open areas), rats were still persisting in a densely-populated colony. Their space use patterns indicate they simply moved elsewhere for food that did not involve cat stalking attempts.

While our results are clear, they should be replicated in areas with a less than continuous food supply. Given the high reproductive rate of city rats(Davis, 1951), when sufficient food is available, one pregnant female can give birth to 6-10 litters of 12 pups each per year. In areas where less food is available, and thus rats are reproducing less frequently, it is possible that the direct effects of predation by cats could be more significant. Further experimental cat control (e.g., data with and without cat presence) is needed to test this phenomenon and to further characterize the effects of cats on rat mortality.

Given that small prey over-estimate risks from predators, further experimentation is also required as to how the presence

\section{REFERENCES}

Apfelbach, R., Parsons, M. H., Soini, H. A., and Novotny, M. V. (2015). Are single odorous components of a predator sufficient to elicit defensive behaviors in prey species? Front. Neurosci. 9:263. doi: 10.3389/fnins.2015. 00263

Bouskila, A., and Blumstein, D. T. (1992). Rules of thumb for predation hazard assessment: predictions from a dynamic model. Am. Nat. 139, 161-176. doi: $10.1086 / 285318$

Carthey, A. J., and Banks, P. B. (2018). Naïve, bold, or just hungry? An invasive exotic prey species recognises but does not respond to its predators. Biol. Invasions 1-13. doi: 10.1007/s10530-018-1782-4

Childs, J. E. (1986). Size-dependent predation on rats (Rattus norvegicus) by house cats (Felis catus) in an urban setting. J. Mammal. 67, 196-199. doi: $10.2307 / 1381025$ of cats, or their scents, indirectly influences the feeding rate (Wernecke et al., 2016) and fecundity (Voznessenskaya, 2014) of rats, and whether this has any tangible benefit as an adjunct to rat control (Himsworth et al., 2013). Such information is essential if we are to understand whether the influence of feral cats on rats is remotely worth the risks to native urban wildlife. Our results at a waste recycling facility, however, suggest that city rats can persist in high density, simply by altering their movements, despite the presence of hunting cats.

\section{DATA AVAILABILITY}

The authors hope our study will lead to future efforts to quantify the impact of cats on rats. Thus, our data will be made available free of charge on request.

\section{AUTHOR CONTRIBUTIONS}

MP designed the study and wrote the article. MP and MD collected all data. PB and JM-S assisted the writing and edits.

\section{FUNDING}

This work was funded by the National Pest Management Association.

\section{ACKNOWLEDGMENTS}

This work was sponsored by the Pest Management Foundation, Fairfax, Virginia. In particular, we thank Jim Fredericks for his assistance throughout the project. We thank Tom Jordan of Arrow Exterminating Company, Inc for MD's time and collaboration. We thank Rudy Fulmer (Arrow) for his ongoing support in provided urban trapping and wildlife monitoring advice. We thank Matt Ruiter and Craig Jordan of UID Identification Solutions for designing the all-weather RFID (PADAR) system for identification of urban rats. Bob Schrock of Vet Equip assisted design of the mobile, anesthesiology unit. We thank Eddie Valentin, Site Manager, for Waste Management (WM) for being extremely helpful in accommodating this research in spite of obligations to ongoing extermination of rats.
Combs, M., Puckett, E. E., Richardson, J., Mims, D., and Munshi-South, J. (2018). Spatial population genomics of the brown rat (Rattus norvegicus) in New York City. Mol. Ecol. 27, 83-98. doi: 10.1111/mec.14437

Davies, H. F., McCarthy, M. A., Firth, R. S., Woinarski, J. C., Gillespie, G. R., Andersen, A. N., et al. (2017). Top-down control of species distributions: feral cats driving the regional extinction of a threatened rodent in northern Australia. Divers. Distrib. 23, 272-283. doi: 10.1111/ddi. 12522

Davis, D. E. (1951). A comparison of reproductive potential of two rat populations. Ecology 32, 469-475. doi: 10.2307/1931724

Embar, K., Raveh, A., Burns, D., and Kotler, B. P. (2014). To dare or not to dare? Risk management by owls in a predator-prey foraging game. Oecologia 175, 825-834. doi: 10.1007/s00442-014-2956-0

Fitzgerald, B., Karl, B., and Veitch, C. (1991). The diet of feral cats (Felis catus) on Raoul Island, Kermadec Group. New Zealand J. Ecol. 15, 123-129. 
Frank, A. S., Johnson, C. N., Potts, J. M., Fisher, A., Lawes, M. J., Woinarski, J. C., et al. (2014). Experimental evidence that feral cats cause local extirpation of small mammals in Australia's tropical savannas. J. Appl. Ecol. 51, 1486-1493. doi: 10.1111/1365-2664.12323

Glanton, D. (2017). Chicago's Rat Problem Gnaws at Feline Fears, Chicago Tribune. Chciago, IL.

Griffith, D. A., and Wong, D. W. (2007). Modeling population density across major US cities: a polycentric spatial regression approach. J. Geogr. Syst. 9, 53-75. doi: 10.1007/s10109-006-0032-y

Herman, C. S., and Valone, T. J. (2000). The effect of mammalian predator scent on the foraging behavior of Dipodomys merriami. Oikos 91, 139-145. doi: 10.1034/j.1600-0706.2000.910113.x

Himsworth, C. G., Feng, A. Y., Parsons, K., Kerr, T., and Patrick, D. M. (2013). Using experiential knowledge to understand urban rat ecology: a survey of Canadian pest control professionals. Urban Ecosyst. 16, 341-350. doi: $10.1007 /$ s11252-012-0261-4

Hurst, J. L., and Beynon, R. J. (2004). Scent wars: the chemobiology of competitive signalling in mice. Bioessays 26, 1288-1298. doi: 10.1002/bies.20147

Jeschke, J. M., Kopp, M., and Tollrian, R. (2002). Predator functional responses: discriminating between handling and digesting prey. Ecol. Monogr. 72, 95-112. doi: 10.1890/0012-9615(2002)072[0095:PFRDBH]2.0.CO;2

Johnson, D. D., Blumstein, D. T., Fowler, J. H., and Haselton, M. G. (2013). The evolution of error: Error management, cognitive constraints, and adaptive decision-making biases. Trends Ecol. Evol. 28, 474-481. doi: 10.1016/j.tree.2013.05.014

Karl, B. J., and Best, H. A. (1982). Feral cats on Stewart Island; their foods, and their effects on kakapo. New Zealand J. Zool. 9, 287-293. doi: 10.1080/03014223.1982.10423857

Kauhala, K., Talvitie, K., and Vuorisalo, T. (2015). Free-ranging house cats in urban and rural areas in the north: useful rodent killers or harmful bird predators? Folia Zool. 64, 45-55. doi: 10.25225/fozo.v64.i1.a6.2015

Kelliher, K. R., and Wersinger, S. R. (2009). Olfactory regulation of the sexual behavior and reproductive physiology of the laboratory mouse: effects and neural mechanisms. ILAR J. 50, 28-42. doi: 10.1093/ilar.50.1.28

Kikillus, K. H., Chambers, G. K., Farnworth, M. J., and Hare, K. M. (2017). Research challenges and conservation implications for urban cat management in New Zealand. Pac. Conserv. Biol. 23, 15-24. doi: 10.1071/PC16022

Loss, S. R., and Marra, P. P. (2017). Population impacts of free-ranging domestic cats on mainland vertebrates. Front. Ecol. Environ. 15:1633. doi: $10.1002 /$ fee. 1633

Loss, S. R., Will, T., and Marra, P. P. (2013). The impact of free-ranging domestic cats on wildlife of the United States. Nat. Commun. 4:1396. doi: $10.1038 /$ ncomms 2380

Montague, M. J., Li, G., Gandolfi, B., Khan, R., Aken, B. L., Searle, S. M., et al. (2014). Comparative analysis of the domestic cat genome reveals genetic signatures underlying feline biology and domestication. Proc. Natl. Acad. Sci. U.S.A. 111, 17230-17235. doi: 10.1073/pnas.1410083111

Naidenko, S. V., Naidenko, S. V., Clark, L., and Voznessenskaya, V. V. (2003). Predator Presence Affects the Reproductive Success of Prey in Outdoor Conditions. Lincoln, NE: USDA

Orrock, J. L., and Danielson, B. J. (2009). Temperature and cloud cover, but not predator urine, affect winter foraging of mice. Ethology 115, 641-648. doi: 10.1111/j.1439-0310.2009.01654.x,

Orrock, J. L., Danielson, B. J., and Brinkerhoff, R. J. (2004). Rodent foraging is affected by indirect, but not by direct, cues of predation risk. Behav. Ecol. 15, 433-437. doi: 10.1093/beheco/arh031

Parsons, M. H., Banks, P. B., Deutsch, M. A., Corrigan, R. F., and Munshi-South, J. (2017). Trends in urban rat ecology: a framework to define the prevailing knowledge gaps and incentives for academia, pest management professionals (PMPs) and public health agencies to participate. J. Urban Ecology 3:jux005. doi: 10.1093/jue/jux005

Parsons, M. H., and Blumstein, D. T. (2010). Feeling vulnerable? Indirect risk cues differently influence how two marsupials respond to novel dingo urine. Ethology 116, 972-980. doi: 10.1111/j.1439-0310.2010.01810.x

Parsons, M. H., Sarno, R., and Deutsch, M. (2015). Jump-starting urban rat research: conspecific pheromones recruit wild rats into a behavioral and pathogen-monitoring assay. Front. Ecol. Evol. 3:146 doi: $10.3389 /$ fevo.2015.00146

Parsons, M. H., Sarno, R. J., and Deutsch, M. A. (2016). A detailed protocol to enable safe-handling, preemptive detection, and systematic surveillance of rat-vectored pathogens in the urban environment. Front. Public Health 4:132. doi: 10.3389/fpubh.2016.00132

Pillay, K. R., Streicher, J., and Downs, C. T. (2018). Home range and habitat use of feral cats in an urban mosaic in Pietermaritzburg, KwaZulu-Natal, South Africa. Urban Ecosyst. 1-11. doi: 10.1007/s11252-018-0766-6

Puckett, E. E., Park, J., Combs, M., Blum, M. J., Bryant, J. E., Caccone, A., et al. (2016). Global population divergence and admixture of the brown rat (Rattus norvegicus). Proc. R. Soc. B 283:20161762. doi: 10.1098/rspb.2016.1762

Rozzi, R., and Lomolino, M. V. (2017). Rapid dwarfing of an insular mammal-the feral cattle of amsterdam island. Sci. Rep. 7:8820. doi: 10.1038/s41598-017-08820-2

Schmidt-Nielsen, B., and O'Dell, R. (1961). Structure and concentrating mechanism in the mammalian kidney. Am. J. Physiol. 200, 1119-1124. doi: 10.1152/ajplegacy.1961.200.6.1119

Siegel, P. S., and Stuckey, H. L. (1947). The diurnal course of water and food intake in the normal mature rat. J. Comparative Physiol. Psychol. 40:365. doi: 10.1037/h0062185

Stanton, L. A., Sullivan, M. S., and Fazio, J. M. (2015). A standardized ethogram for the felidae: a tool for behavioral researchers. Appl. Anim. Behav. Sci. 173, 3-16. doi: 10.1016/j.applanim.2015.04.001

Takács, S., Gries, R., Zhai, H., and Gries, G. (2016). The sex attractant pheromone of male brown rats: identification and field experiment. Angew. Chem. Int. Edn. 55, 6062-6066. doi: 10.1002/anie.201511864

Themb'alilahlwa, A., Monadjem, A., McCleery, R., and Belmain, S. R. (2017). Domestic cats and dogs create a landscape of fear for pest rodents around rural homesteads. PLoS ONE 12:e0171593. doi: 10.1371/journal.pone.0171593

Voznessenskaya, V. V. (2014). Influence of cat odor on reproductive behavior and physiology in the house mouse (Mus musculus). Neurobiol. Chem. Commun. 389-406. doi: 10.1201/b16511-15

Voznessenskaya, V. V., Naidenko, S. V., Feoktistova, N. Y., Krivomazov, G. J., Miller, L. A., and Clark, L. (2003). Predator Odours as Reproductive Inhibitors for Norway Rats. USDA National Wildlife Research Center-Staff Publications. Boca Raton, FL: CRC Press.

Wernecke, K. E., Brüggemann, J., and Fendt, M. (2016). Predator odor exposure increases food-carrying behavior in rats. Physiol. Behav. 154, 15-19. doi: 10.1016/j.physbeh.2015.11.005

Woinarski, J., Murphy, B., Legge, S., Garnett, S., Lawes, M., Comer, S., et al. (2017). How many birds are killed by cats in Australia? Biol. Conserv. 214, 76-87. doi: 10.1016/j.biocon.2017.08.006

Yip, S. J., Rich, M.-A., and Dickman, C. R. (2015). Diet of the feral cat, Felis catus, in central Australian grassland habitats during population cycles of its principal prey. Mammal Res. 60, 39-50. doi: 10.1007/s13364-014-0208-7

Zhou, N., Fridley, D., Khanna, N. Z., Ke, J., McNeil, M., and Levine, M. (2013). China's energy and emissions outlook to 2050: Perspectives from bottom-up energy end-use model. Energy Policy 53, 51-62. doi: 10.1016/j.enpol.2012.09.065

Zielinski, W. J., vom Saal, F. S., and Vandenbergh, J. G. (1992). The effect of intrauterine position on the survival, reproduction and home range size of female house mice (Mus musculus). Behav. Ecol. Sociobiol. 30, 185-191. doi: $10.1007 /$ BF00166702

Conflict of Interest Statement: The authors declare that the research was conducted in the absence of any commercial or financial relationships that could be construed as a potential conflict of interest.

Copyright (c) 2018 Parsons, Banks, Deutsch and Munshi-South. This is an open-access article distributed under the terms of the Creative Commons Attribution License (CC $B Y)$. The use, distribution or reproduction in other forums is permitted, provided the original author(s) and the copyright owner(s) are credited and that the original publication in this journal is cited, in accordance with accepted academic practice. No use, distribution or reproduction is permitted which does not comply with these terms. 